\title{
Estimation of unconfined compressive strength of cement-stabilized jabre as material upgrade on highway construction
}

\author{
E. Teijón-López-Zuazo ${ }^{\mathrm{a}}$, Á. Vega-Zamanillo ${ }^{\mathrm{b}}$, M. Á. Calzada-Pérez ${ }^{\mathrm{b}}$, L. Juli-Gándara $^{\mathrm{b}}$ \\ a. Construction and Agronomy Department, Zamora Polytechnical School, University of Salamanca, (Zamora, Spain) \\ b. Department of Transportation and Projects and Processes Technology. Civil Engineering Technical \\ School of Santander, University of Cantabria, (Santander, Spain) \\ \eteijon@usal.es
}

Received 10 June 2019

Accepted 11 December 2019

Available on line 12 May 2020

\begin{abstract}
Granite rock has powerful alterations at several meters of depth. The clayed sand resulting is commonly known as jabre. This "in situ" mixture of cement-stabilized soil requires a laboratory formula. Even when the test section is correctly verified, the mechanical properties of the homogeneous mixture of jabre exhibit high degrees of dispersion. The laboratory work undertaken included particle-size analysis and screening, definition of liquid and plastic limits, compressive strength, dry density and moisture content over stabilized samples, modified Proctor, California Bearing Ratio (CBR) and the determination of the workability of the hydraulically bound mixtures. The stress resistance curve was analyzed by means of a multilinear model of unconfined compressive strength (UCS). Since practical engineering only requires UCS for 7 days, in order to gain greater knowledge of the material, other UCS transformations were used at other curing times such as 7, 14 and 28 days.
\end{abstract}

KEYWORDS: Granite; Blended cement; Curing; Compressive strength; Modelization.

Citation/Citar como: Teijón-López-Zuazo, E.; Vega-Zamanillo, Á.; Calzada-Pérez, M. Á.; Juli-Gándara, L. (2020) Estimation of unconfined compressive strength of cement-stabilized jabre as material upgrade on highway construction. Mater. Construcc. 70 [338], e218 https://doi.org/10.3989/mc.2020.09019

RESUMEN: Estimación de la resistencia a compresión simple del jabre estabilizado "in situ" con cemento como material en la formación de explanadas de carreteras. La roca granítica presenta habitualmente un horizonte de alteración con varios metros de potencia. La arena arcillosa resultante como producto de alteración se denomina comúnmente jabre. Aunque la fórmula de trabajo de la estabilización de jabre con cemento se verifique correctamente en tramos de prueba, la estabilización "in situ" del jabre con cemento presenta habitualmente elevadas dispersiones. Entre los ensayos de laboratorio efectuados se encuentran los ensayos de análisis granulométrico, límites de Atterberg, resistencia a compresión simple (RCS), la densidad y humedad sobre probetas de suelo estabilizado, Proctor modificado, índice CBR (California Bearing Ratio) y el plazo de trabajabilidad de la mezcla con cemento. La curva de endurecimiento del suelo estabilizado fue ajustada mediante un modelo multilineal. Aunque tradicionalmente se especifique la RCS a 7 días, buscando definir un mejor comportamiento del material, los autores calcularon otros modelos de jabre estabilizado para roturas a 7, 14 y 28 días.

PALABRAS CLAVE: Granito; Cemento con adiciones; Curado; Resistencia a la compresión; Modelización.

ORCID ID: E. Teijón-López-Zuazo (https://orcid.org/0000-0002-9962-4846); Á. Vega-Zamanillo (https://orcid. org/0000-0002-7140-6329); M. Á. Calzada-Pérez (https://orcid.org/0000-0001-6528-9392); L. Juli-Gándara (https://orcid.org/0000-0003-1802-7191).

Copyright: (C) 2020 CSIC. This is an open-access article distributed under the terms of the Creative Commons Attribution 4.0 International (CC BY 4.0) License. 


\section{INTRODUCTION}

The granitic alluvial soil that results from the alteration of granite rock is a type of clayed sand known as "jabre". Jabre has high unconfined compressive strength (UCS), which is the most important property of the improved cement subgrade and the main tested property in quality control for subgrade formation. Even if cement spread rate is correctly sized in the laboratory, cement-stabilized jabre is usually associated with high dispersion of UCS values. Since unconfined compressive strength (UCS) is the most important property of the improved cement subgrade, dispersion triggered by changes in the alteration grades of jabre can be predicted using a multilinear model, therefore preventing negative UCS results. Accordingly, the main purpose is to define the mechanical properties of jabre based on its different characteristics in association with the different alteration grades of granitic rock. The specific objectives are to analyze how the main properties of the soil influence unconfined compressive strength and to define the hardening curve for the estimation of mechanical resistance after cementstabilization at different times.

As described by García-Talegón et al. (1), variations are based on the origin of the decomposed granite and its degree of alteration. Granite alluvial soil consists of deposits formed from the alteration of granite. It is made up of whitish granite quartz sand grains and a clayed fraction coming from the total alteration of feldspars. The high content of feldspars can be translated into jabre with a higher clay fraction. The main natural alteration of these minerals yields kaolinite clay $\left(\mathrm{Al}_{2} \mathrm{Si}_{2} \mathrm{O}_{5}(\mathrm{OH})_{4}\right)$. Granite-rock alluvial deposits are thicker than others associated with metamorphic lithologies and can reach thicknesses of several meters. Thus, granite massifs are affected by orthogonal joint sets. If it advances deeper, the rocks become divided into parallel piped blocks. The fracture web allows the partial alteration of the feldspars by cold water, transforming them into pure clay. This kaolinite is washed by the water leaving a sandy residue of unaltered quartz, mica and feldspar grains. Later, rainwater washes away the sand material leaving groups of rocks in unstable equilibrium (granitic towers). When this equilibrium is broken, stone build-ups are formed in the ridges and the sands become deposited in the lower areas. A generalized fact regarding granitic rock is the presence of powerful alterations that affect the plinth in several meters of depth, leading to an important silicification on its top layer. Alteration and silicification are two separate processes. The weathering process is related to climate changes, from the wettest (clayish alteration) to more prone to aridity seasons (sandstone silicification). The thickness of the alteration layer, which can exceed $18-20 \mathrm{~m}$, includes 3 levels: the lowest, made up of light-gray boluses; the intermediate, which is 4-5 $\mathrm{m}$ deep and completely sandy; and, finally, a highly silicified level, with variations of red-ocher-white colors resulting from hydromorphic processes.

Champire et al. (2) have demonstrated the impact of relative humidity variations on the deformability and strength of unstabilized earth. Their tests were performed on different compacted earth samples conditioned at different relative humidity levels, including unconfined compression tests, with and without unload-reload cycles. Nevertheless, the materials coming from different existing constructions and sieved at $10 \mathrm{~mm}$ are definitely different from weathered granitic soil.

"In situ" cement mixing cannot start until the spread rate is defined. Meanwhile, a preliminary study must be adjusted through a laboratory test and, eventually, a road section test. Stabilized soil samples, according to UNE-EN 13286-51 (3), have to meet certain requirements. Under these circumstances, S-EST3 is the best kind of cement-stabilized soil (4), appropriate for subgrade improvement in highway construction. It requires a minimum cement content (C) of $3.0 \%$ over dry soil, with UCS at seven days of curing (7d) of $1.5 \mathrm{MPa}$, in accordance with standard UNE-EN 13286-41 (5). Additionally, its compaction rate as determined by modified Proctor should report a maximum density above $98 \%$, following UNE 103 501 (6) and UNE 103900 (7); a passing fraction below $35 \%$ in $0.063 \mathrm{~mm}$, according to UNE-EN $933-2$ (8) and UNE 103101 (9); plasticity values where the liquid limit (LL) is below 40, following UNE 103103 (10); and a plasticity index (PI) below 15, according to UNE 103103 and UNE 103104 (11).

Anagnostopoulos, CA (12) examined the use of novel soil strengthening materials, studying the potential use of epoxy resins to improve mechanical properties such as UCS. The strength of most of the epoxy resin-treated soil samples seemed to improve noticeably after 90 days of curing. The addition of cement significantly improved the strengths of all mixes at all curing ages. Therefore, this increment in strength could be mainly attributed to the consumption of large quantities of water from cement compounds.

Niu et al (13) assessed the effects of clay content on the mechanical properties of compacted weathered granite using the compaction test and the California Bearing Ratio (CBR) test on samples with four different measures of clay content: $4,8,10$, and $12 \%$. Laboratory test results indicated that the $8 \%$ clay content measure could be a good indicator to define the compaction characteristics of weathered granite with different clay contents. Thus, clay contents of around 8\% would benefit subgrade compaction rates and, thus, road stability. Even so, the CBR of strong weathered granite with around $4 \%$ clay content is the greatest, with an index of 95. 
Although Wu et al (14) have argued that, compared to other granular materials, the axial strain of jabre is the largest at the same axial load level due to its mineral hardness, experimental results demonstrate that the crushing degree of granular material is greatly influenced by loading modes and conditions.

Kariyawasam and Jayasinghe (15) indicate that producing a stabilizing earth, with cement and ramming at optimum moisture content, forms cement stabilized rammed earth (CSRE). While it is a building material with sufficient strength and durability, it is low in embodied energy. The sandy laterite soil available in tropical regions, which has similar properties to those of jabre, has been identified as a better ingredient for CSRE construction. This can offer adequate compressive and flexural strengths when cement content is above 6\% in road construction.

Experimental studies on compression tests have attracted the attention of many researchers. Kasama et al. (16), for instance, developed a technique called cement-mixing and mechanical dehydration (CMD) that is aimed at examining the effect of a specimen's physical properties on its compression behavior. For decomposed granite, they propose a multiple linear regression function including plastic limit, degree of saturation and water-cement ratio.

Liu et al. (17), have carried out in-depth research on clayey rocks. Their experimental results show that the increase of deviatoric stress enhances the creep strain, which clearly exhibits anisotropic behavior, and that the inelastic creep deformation induces an increase of the long-term compressive strength of argillite.

Another significant aspect of UCS prediction for long curing periods is approached by Saldanha et al. (18), who develop a technique that enables the use of standard laboratory curing temperature $\left(23^{\circ} \mathrm{C}\right)$ through prediction equivalence with accelerated curing, using temperatures of 40 and $60^{\circ} \mathrm{C}$.

Fernandez-Ledesma et al. (19) believe in the need to avoid serious environmental harm by using fine fraction from recycling concrete as a construction material. Thus, they engaged in defining the maximum replacement level of natural sand with recycled sand in masonry mortar (M-10). Five replacement levels were tested according to volume: $0 \%, 25 \%, 50 \%, 75 \%$ and $100 \%$. Mixes were made using cement CEM II/BL $32.5 \mathrm{~N}$ in a $1: 5$ volumetric proportion of cement-to-aggregate.
The amount of water was variable to achieve a consistency of $175+/-10 \mathrm{~mm}$. Finally, the conclusion reached was that the maximum percentage of recycled concrete sand that can be used in an indoor environment is $50 \%$.

\section{MATERIALS AND METHODS}

The materials and clustering investigated are part of the cement stabilized subgrade phase in road construction, used for the A-66 road (European E-803), Caceres $(\mathrm{N})$ - Aldea del Cano section, which is over $31 \mathrm{~km}$ long and is split into two separate carriageways. In general, cement-stabilized jabre has high UCS, so these materials can be used as base layers.

Initially, more than 300 samples were tested for identification and provenance. For resistance characterization purposes, more than 1.500 breaks of test pieces of cement-stabilized soil were made. On site controls were applied at more than 7.500 points, estimating density and humidity. More than 200 load plate tests were carried out following UNE 103 808 (20). All the tests were distributed into more than 750 control shares.

During the stabilization process, Portland cement was used, specifically, CEM II / B-M (P-V-L) $32.5 \mathrm{~N}$ according to RC-16 (21). The clinker content of this cementitious binder is between $65-79 \%$. The rest of the components are additions such as natural pozzolans, siliceous ash and limestone. The binder dosage was controlled using weighing devices included in the stabilization equipment. These were easily verified counting cement binder tanks. Compaction control was based on the percentage of modified Proctor density.

UCS was assessed on day seven together with compaction rate according to modified Proctor. The specimens were manufactured with the degree of compaction reached at work (98\% modified Proctor density in this case). The value corresponds to the embankment compaction degree which is was required in highway construction. Measures were produced with a vibratory compaction hammer in fieldwork and using a manual or mechanical compactor in the laboratory, always during the workability timeframe of workability, as established in UNE-EN 13286-45 (22). The resulting measurements were categorized into three groups, as shown in Table 1. After the initial identification phase, more than 200 samples

TABLE 1. Classification of alluvial soil sample identification trials

\begin{tabular}{|c|c|c|c|c|c|c|c|c|}
\hline \multirow[b]{2}{*}{ group } & \multirow[b]{2}{*}{ number of samples } & \multicolumn{3}{|c|}{ sieving } & \multirow[b]{2}{*}{$\mathbf{L L}$} & \multirow[b]{2}{*}{ PI } & \multicolumn{2}{|c|}{ modified Proctor } \\
\hline & & $80 \mathrm{~mm}$ & $2.0 \mathrm{~mm}$ & $0.08 \mathrm{~mm}$ & & & $d_{\max }\left(\mathrm{g} \mathrm{cm}^{-3}\right)$ & $\mathrm{H}_{\text {opt }}(\%)$ \\
\hline I & 42 & 100.0 & 50.0 & 13.5 & 33.8 & 7.0 & 2.06 & 8.2 \\
\hline II & 30 & 100.0 & 47.0 & 9.7 & 32.4 & 4.4 & 2.09 & 7.7 \\
\hline III & 26 & 100.0 & 44.5 & 9.6 & 36.7 & 10.3 & 2.08 & 7.6 \\
\hline
\end{tabular}


were made during the "in situ" stabilization of jabre with cement to determine the main identification parameters and the UCS. The minimum percentage of cement binder at "in situ" stabilization was 3.5\% (over dry soil). Laboratory samples were made for 12 different contents within a $2.0-6.0 \%$ interval. Plate load tests should be conducted after 14 or $28 \mathrm{~d}$, when the main hardening is finishing.

More than 1.000 ruptures were made from the samples using a vibrating hammer on site for stabilization purposes. Another 500 specimens were mixed with cement in the laboratory using a concrete mixer. More were ruptured at different curing ages $(3,7,14$ and $28 \mathrm{~d})$. Other standard tests were also run, such as the 100 Modified Proctor, the 90 Atterberg limits and the 90 test grading.

The tests were carried out during quality control, alongside initial identification and definition studies and subsequent control and adjustment during execution. The stabilized soil measure was of $660000 \mathrm{~m}^{3}$ and the on-site stabilization surface was over $1300000 \mathrm{~m}^{2}$. Before defining the cement mixture, measures were split into 3 groups with similar characteristics, thus preventing dispersion. Table 2 shows the sampling and average values of quality control construction.

In general, they are predominantly sandy soils with a small fraction of gravel. Plasticity is medium-low, and they are defined as SC (clayed sands) in the USUCS classification. Their appearance is grayish with whitish veins. The specimens present a minimum aggregate content (grading above $2-\mathrm{mm}$ ) of $35 \%$. Additionally, they have a fine aggregate content of between 6-35\%. Jabre is an alluvial soil that is associated with the alteration grade of granitic rock. In general, it has a thickness between $1.0-2.0 \mathrm{~m}$. It consists of deposits of whitish granitic quartzite sand and a clayed fraction resulting from feldspar alteration. This implies that Liquid limit (LL) values are close to 40 and the plasticity index is close to 15 . The Atterberg limits report medium - low plasticity. Attention should also be paid to its remarkably high quality, which allows it to be used for subgrades.

Before defining the cement mixture, samples were taken at different depths from each of the planed diggings and extractions. The resulting measurements were classified into 3 groups that shared similar characteristics to avoid dispersion. Cement tests were performed for each group for identification and stabilization purposes.

All the mentioned quality tests were processed grouping the esplanade into 500 representative sections of similar characteristics. Thus, the correlations, laboratory tests and tests carried out on site were added for possible effects. This section describes the statistical techniques that were used to produce a model to estimate resistances from the main control parameters, which were developed in order to analyze test differences.

Thus, a multilinear adjustment model of the UCS characteristic curve for stabilized jabre was been developed. UCS was monitored as a predictive value, improving quality control optimization. Other UCS models at different curing ages $(7,14$ and $28 \mathrm{~d}$ ) were also adjusted. A positive linear correlation between UCS and share density, the $2 \mathrm{~mm}$ sieve and the filler / cement binder ratio enables UCS to be used to inter-decrease mechanical properties.

Soil identification tests and cement-stabilized ruptures allow the detection of flaws with the UCS model of jabre-stabilization. This has improved the use of jabre as a stabilized soil, controlling soil parameters "in situ". Statistical models were estimated using IBM SPSS Statistics.

Seeking the best statistical fit, shams were regrouped into more than 450 control shares. All of them were tested for UCS, plasticity and grading. Analysis of variance ANOVA was applied to introduce variables. If there were low levels of significance, they were removed. The variables used in the multivariate analysis of UCS were the following: $2.0 \mathrm{~mm}$ sieving, fine aggregate $(0.08 \mathrm{~mm}), \mathrm{LL}, \mathrm{PI}$, $\mathrm{C}$, dry density over sample in $\mathrm{g} \mathrm{cm}-3\left(\mathrm{~d}_{\mathrm{sm}}\right)$, moisture

TABLE 2. Physical parameters for initial jabre identification (average parameters in last row)

\begin{tabular}{lccccccccc}
\hline \# 100.0 & \# 20.0 & \# 2.0 & \# 0.40 & \# 0.08 & LL & PI & $\mathbf{d ~ ( \mathbf { g ~ c m } ^ { - 3 } )}$ & H (\%) & CBR \\
\hline 100.0 & 98.0 & 65.0 & 35.0 & 17.5 & 37.4 & 9.5 & 2.00 & 8.8 & 29.2 \\
100.0 & 100.0 & 48.0 & 23.0 & 11.6 & 30.6 & 3.5 & 2.12 & 6.4 & 42.7 \\
100.0 & 98.0 & 45.0 & 20.0 & 9.0 & 31.9 & 7.6 & 2.11 & 6.1 & 46.3 \\
100.0 & 74.0 & 52.0 & 24.0 & 11.0 & 28.4 & 6.2 & 2.12 & 7.4 & 50.6 \\
100.0 & 100.0 & 60.0 & 25.0 & 12.6 & 0.0 & 0.0 & 2.04 & 10.0 & 78.0 \\
100.0 & 99.0 & 37.0 & 13.0 & 9.0 & 40.4 & 15.2 & 2.09 & 9.0 & 29.1 \\
100.0 & 94.0 & 35.0 & 16.0 & 8.6 & 32.8 & 6.9 & 2,06 & 6.1 & 36.1 \\
100.0 & 96.0 & 66.0 & 29.0 & 14.8 & 37.8 & 11.4 & 2.00 & 7.7 & 28.2 \\
100.0 & 100.0 & 80.0 & 55.0 & 40 & 43.7 & 17.6 & 2.04 & 8.6 & 15.2 \\
100.0 & 95.9 & 53.0 & 25.4 & 13.6 & 29.0 & 8.1 & 2.07 & 8.2 & 40.7 \\
\hline
\end{tabular}


content over sample, rupture time in days $(\mathrm{t})$, dry density over compaction shares, moisture content over shares, maximum modified Proctor density, optimum moisture modified Proctor, compaction rate over sample, compaction rate over share, differences between sample and optimum modified Proctor moistures, first and second vertical compressive modulus plate-bearing test, relation between second/first vertical compressive modulus, moisture content over share and cement binder relation, relation between fine aggregate and cement (fn/C).

The association of independent variables with the dependent variable (compression resistance) was determined using Student's t test. The independent variables that obtained low absolute values in the the t-test were removed due to their lack of significance in the statistical adjustment.

\section{RESULTS}

UCS is the fundamental parameter of cement improved subgrades. Thus, the high variability in granitic eluvial soils, allows the development of a linear regression model. This UCS estimate depends on the granulometry, rate of cement spread and degree of compaction over samples. In these cases, soil stabilization with $\mathrm{UCS} \geq 1.5 \mathrm{MPa}(7 \mathrm{~d}$ rupture) (4) is often met with the minimum dosage $(3.0 \%)$. It should be also mentioned that jabre is still a developing material. Another important control parameter is the degree of compaction, which defines the minimum density in representative samples. Consequently, there was a probability above 0.95 that the compressive strengths of specimens could be calculated using the model. Because of this robustness, the model allows for the prediction of resistance with potential dispersion associated with the particularities of the soil. UCS tests over stabilized soil were related to others such as identification tests, on site density determination or plate-bearing tests. Thus, a total of 462 control lots were used.

Mixtures that made with different percentages of cement were produced, with UCS at curing ages 7 , 14 and 28d. Every UCS was the average value of 3 ruptured samples.

In general, average resistances higher than normal were obtained (1.5 MPa) for all the percentages of cement binder, even for the $3.0 \%$ minimum content. Moreover, the minimum setting time period of workability of cement improved soil (standard UNE-EN 13286-45) and was 180 minutes.

The following subsections describe different models calculated for UCS in cement-stabilized jabre, considering all the properties that could produce a loss of mechanical resistance. There are models for the stress curve and UCS at seven 7, 14 and $28 \mathrm{~d}$ curing. Transformations of UCS (logarithm, exponential) were also analyzed.
To sum up, the multivariate analysis offered a generalized multilinear model for the stress curve and the cubic-root transformation for UCS at 7, 14 or $28 \mathrm{~d}$. After the analysis of all the independent variables in previous chapters, the $2.0 \mathrm{~mm}$ sieve and share density appeared as common variables in all the UCS models.

\subsection{Cement-stabilized jabre stress curve}

The variables introduced in the model proved robust for a multilinear approach, with linear UCS (t) as a dependent variable. The independent indicators were rupture times and the variables with the highest goodness-of-fit, which were sand and fine aggregate (sieve $2 \mathrm{~mm}$ ), share density and cement content.

The results in Table 3 show the fit of the model. Pearson's correlation coefficient values are 0.848 and the determination coefficient is 0.729 , with a standard error of 0.2799 , which proves low dispersion of multilinear adjustment.

The scatterplot for Figure 1 shows a correlation between share density and compression strength. The statistic link is directly proportional and the highest density values correspond to greater resistances. This trend is repeated for each of the curing ages $(7,14$ or 28 days).

Table 4 below shows the parameters yielded by the analysis of variance (ANOVA). Significance according to Levene's was 0.000 , with an F value of 85.313. Therefore, the null hypothesis of homoscedasticity is rejected. Variances are significantly different. In this case, the variance of UCS ( $t$ ) appears to be conditioned by the dependent variables, which are rupture ages, share densities, cement contents and $2.0 \mathrm{~mm}$ sieving.

TABLE 3. Determination coefficients for UCS ( $\mathrm{t}$ ) path model of jabre

\begin{tabular}{lccc}
\hline \multicolumn{3}{c}{ Summary model } \\
\hline $\mathbf{R}$ & $\mathbf{R}^{\mathbf{2}}$ & adjusted $\mathbf{R}^{\mathbf{2}}$ & standard error \\
\hline $0.848^{\mathrm{a}}$ & 0.720 & 0.711 & 0.2799 \\
\hline
\end{tabular}

a predictors: constant, \#2.0mm (\%), t (d), C (\%), $\mathrm{d}_{\mathrm{sm}}\left(\mathrm{g} \mathrm{cm}^{-3}\right)$.

TABLE 4. Analysis of variance for UCS ( $\mathrm{t}$ ) path model in jabre

\begin{tabular}{lccccc}
\hline \multicolumn{5}{c}{ ANOVA $^{\mathrm{a}}$} \\
\hline model & $\begin{array}{c}\text { squares } \\
\text { Sum }\end{array}$ & $\begin{array}{c}\text { degrees of } \\
\text { freedom }\end{array}$ & average & F & sig. \\
\hline regression & 26.739 & 4 & 6.685 & 85.313 & $0.000^{\mathrm{b}}$ \\
remainder & 10.421 & 133 & 0.078 & & \\
Total & 37.160 & 137 & & & \\
\hline
\end{tabular}

a dependent variable: UCS (t) $(\mathrm{MPa})$.

bredictors: constant, \#2.0mm (\%), t (d), C (\%), $\mathrm{d}_{\mathrm{sm}}\left(\mathrm{g} \mathrm{cm}^{-3}\right.$.) 
The scatterplot in Figure 2 shows a correlation between sieving with a $2 \mathrm{~mm}$ sieve and compression resistance. A total of 137 shares were tested for grading and compression strength. The statistical link is directly proportional to 2 millimeters sieving when higher levels of sieving correspond to higher compression strength.

According to the graph, it is difficult to pair variables because of their low level of similarity. Consequently, Table 5 presents t-values in a multilinear regression model with 3 variables. Student's t-test yielded high values, with modules between 6.437 and 12.930. All the variables proved significant (0.000), leading to the conclusion that the independent variables have a significant impact on compression strength at any time.

The distribution of shares in Figure 3 shows a correlation between the cement binders and UCS. Higher binder contents correspond to larger resistances. Correlations between variables taken in pairs is low, but in a multilinear analysis with the 3 variables together, the correlation coefficient shows a high value.

With the coefficients of multicollinear regression, the accuracy of the results in the UCS in jabre

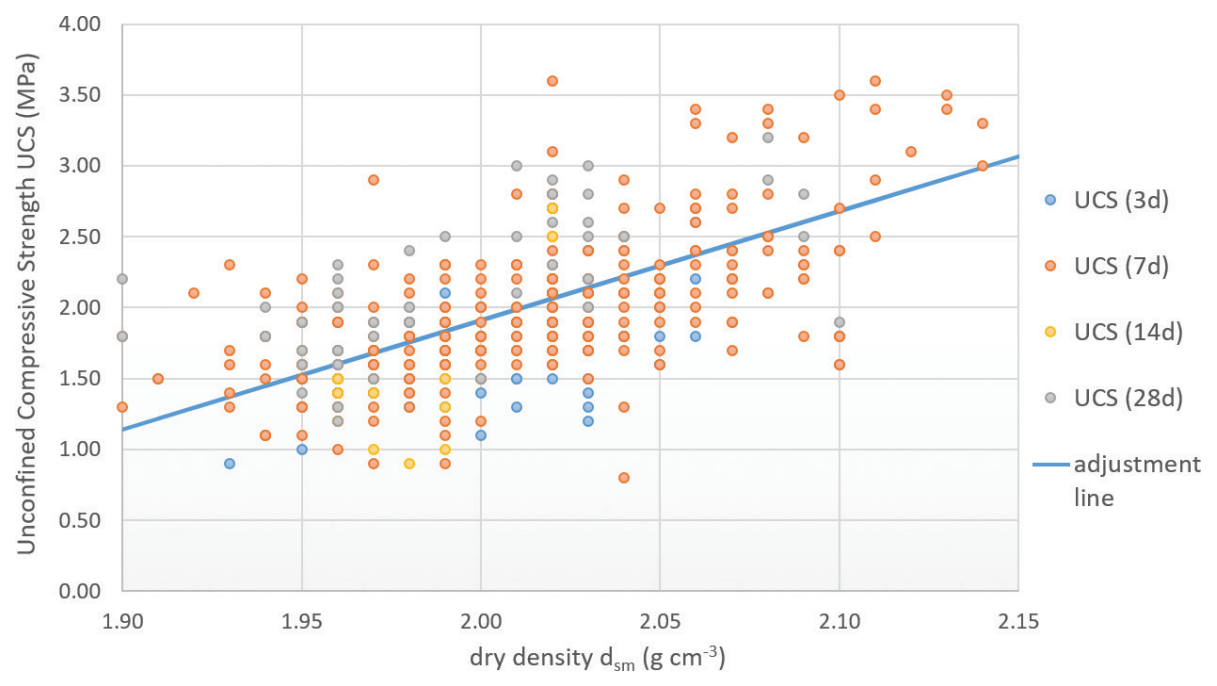

FIGURE 1. Relationship between dry density $\mathrm{d}_{\mathrm{sm}}$ and Unconfined Compressive Strength UCS $(3,7,14 \& 28 \mathrm{~d})$

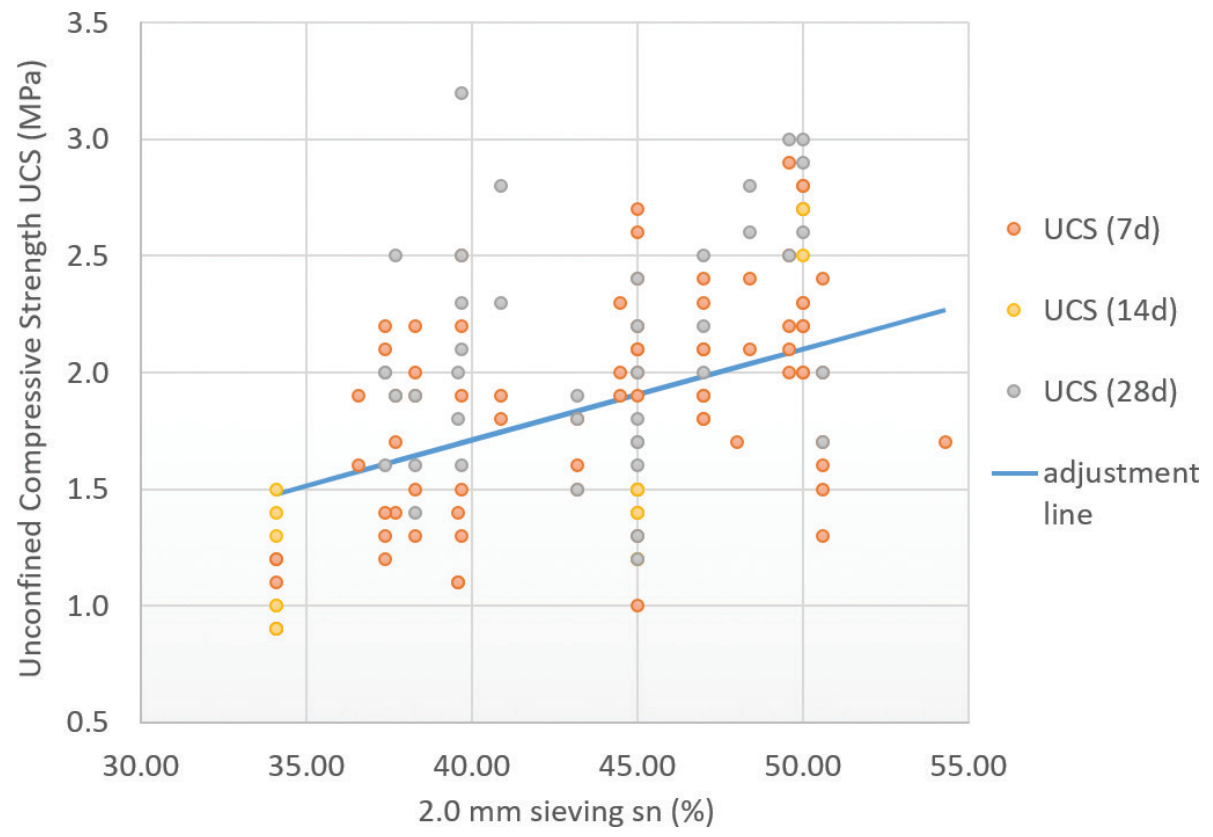

FIGURE 2. 2.0mm sieving versus Unconfined Compressive Strength UCS (7, 14 \& 28d rupture time) 
cement-stabilized diagram can be explained with the Equation [1]:

$$
\begin{aligned}
\mathrm{UCS}(\mathrm{t})= & 7.705 \cdot \mathrm{d}_{\mathrm{sm}}+0.149 \cdot \mathrm{C}+0.039 \cdot \# 2.0 \mathrm{~mm}+ \\
& 0.017 \cdot \mathrm{t}-16.031
\end{aligned}
$$

where UCS $(\mathrm{t})$ is unconfined compressive strength $(\mathrm{MPa})$ at $\mathrm{t}$ rupture time $(\mathrm{d}), \mathrm{d}_{\mathrm{sm}}$ dry density over sample $\left(\mathrm{g} \mathrm{cm}^{-3}\right), \mathrm{C}$ cementitious binder percentage (over dry soil) and two-millimeter sieving (\% \#2.0 mm).

The significance has a validity range. UCS (t) has a range of distribution between 0.7 and 3.6 $\mathrm{MPa}$. Rupture time is from 7d until 28d. Density samples are between 1.90 and $2.14 \mathrm{~g} \mathrm{~cm}-3$. Cement content is between 2.0 and 6.0 . Finally, the $2.0 \mathrm{~mm}$

TABLE 5. Multilinear regression coefficients for UCS ( $t$ )

\begin{tabular}{|c|c|c|c|c|c|}
\hline \multicolumn{6}{|c|}{ coefficients $^{\mathrm{a}}$} \\
\hline \multirow[b]{2}{*}{ Model } & \multicolumn{2}{|c|}{$\begin{array}{c}\text { nonstandard } \\
\text { coefficients }\end{array}$} & \multirow{2}{*}{$\begin{array}{c}\begin{array}{c}\text { standard } \\
\text { coefficients }\end{array} \\
\beta \\
\end{array}$} & \multirow[b]{2}{*}{$t$} & \multirow[b]{2}{*}{ sig. } \\
\hline & B & $\begin{array}{c}\text { standard } \\
\text { error }\end{array}$ & & & \\
\hline constant & -16.031 & 1.240 & & -12.930 & 0.000 \\
\hline t (d) & 0.017 & 0.003 & 0.314 & 6.698 & 0.000 \\
\hline $\mathrm{d}_{\mathrm{sm}}\left(\mathrm{g} \mathrm{cm}^{-3}\right)$ & 7.705 & 0.640 & 0.586 & 12.037 & 0.000 \\
\hline $\mathrm{C}(\%)$ & 0.149 & 0.023 & 0.300 & 6.413 & 0.000 \\
\hline$\# 2.0 \mathrm{~mm}(\%)$ & 0.039 & 0.005 & 0.391 & 8.084 & 0.000 \\
\hline
\end{tabular}
path model in jabre

dependent variable: $\mathrm{UCS}(\mathrm{t})(\mathrm{MPa})$. sieving (medium sand \& filler content) is between 34.1 and $54.3 \%$.

\subsection{Compressive strength model. Rupture at seven days of curing (7d)}

The variables introduced into the model were as follows: the dependent variable was UCS transformation cubic-root; and the independent variables were the three whose indicators had obtained the best results, namely sand and fine aggregate (passing fraction two millimeters), share density and water-cement ratio. Table 6 includes the model summary where the coefficient of determination is 0.684 , which is naturally associated with a high Pearson's product-moment correlation coefficient of 0.844 . There is a low standard error of 0.2986 and the parameters indicate high probabilities of goodness-of-fit.

In general, higher share densities are associated with higher compressions, while higher contents of sand and filler (sieving \#2.0mm) corresponded to lower UCS (7d). The ANOVA analysis yielded the parameters shown in Table 7. Levene's test $(\mathrm{F})$ yielded an $\mathrm{F}=60.914$ value with the maximum significance $(\mathrm{Sig}=0.000)$ for 83 degrees of freedom. Due to this, it complies with homoscedasticity. Variances are significantly different, so that the UCS (7d) cubic root is related to the sand and fine aggregate content, the densities and the filler/cementitious binder ratio.

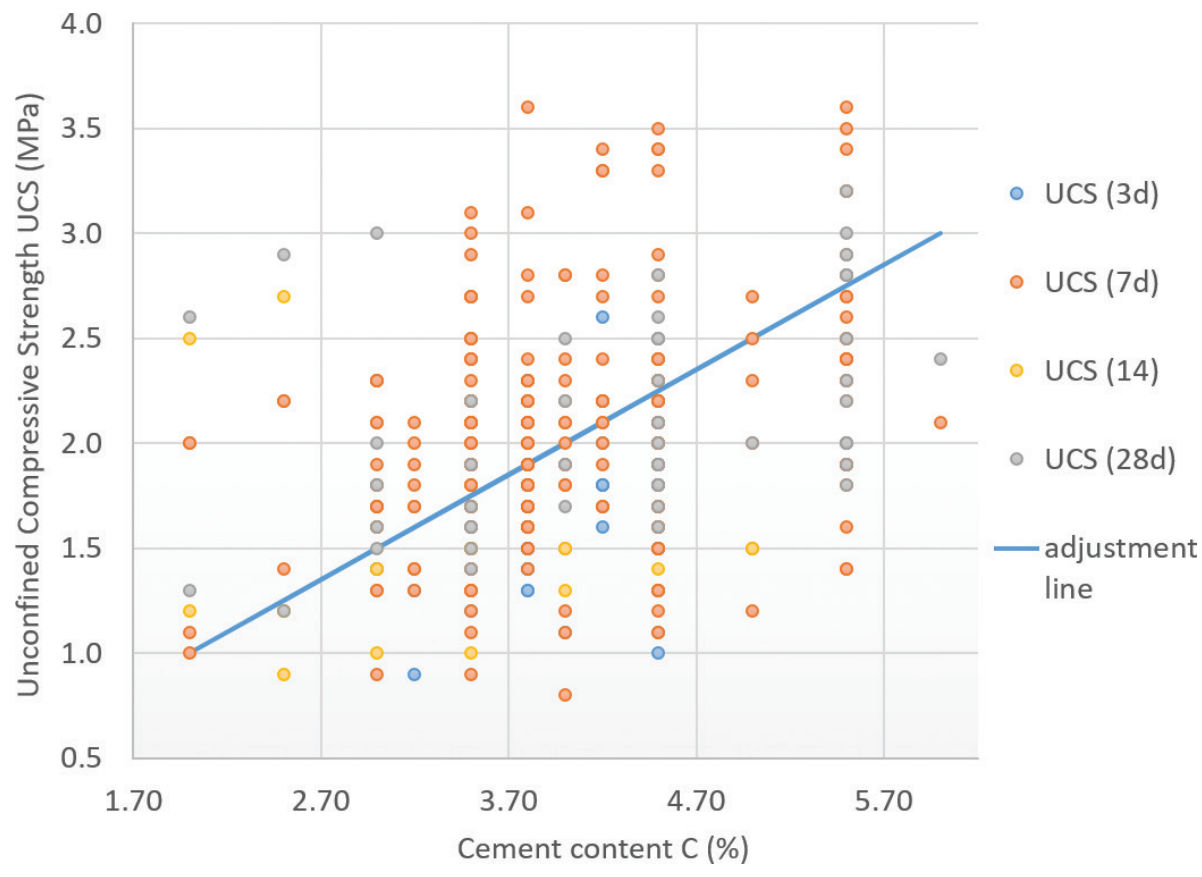

Figure 3. Cement content C versus Unconfined Compressive Strength UCS (3, 7, 14 \& 28d rupture time) 
t-test results are shown in Table 8 with a high value of the $t$ statistic, between $2.364-13.002$. All the variables are significant $(\mathrm{sig}<0.050)$, with probability degrees between 0.000 and 0.020 .

Under these circumstances, the UCS time cluster $(7 \mathrm{~d})$ is represented by the following Equation [2]:

$$
\begin{aligned}
& \sqrt[3]{\operatorname{UCS}(7 \mathrm{~d})}=2.777 \mathrm{~d}_{\mathrm{sm}}+0.171 \frac{\# 0.08 \mathrm{~mm}}{\mathrm{C}} \\
& -0.016 \# 2 \mathrm{~mm}-4.111
\end{aligned}
$$

where $\mathrm{d}_{\mathrm{sm}}$ is sample density $\left(\mathrm{g} \mathrm{cm}^{-3}\right), \operatorname{UCS}(7 \mathrm{~d})$ compressive strength at $7 \mathrm{~d}(\mathrm{MPa}), \# 0.08 \mathrm{~mm} / \mathrm{C}$ relate fine aggregate $(\% \# 0.08 \mathrm{~mm})$ and cementitious binder (over dry soil), \#2.0 UNE two millimeters sieving.

TABLE 6. Determination coefficients for UCS (7d) model in jabre

\begin{tabular}{lccc}
\hline \multicolumn{3}{c}{ Model Summary } \\
\hline $\mathbf{R}$ & $\mathbf{R}^{\mathbf{2}}$ & adjusted $\mathbf{R}^{\mathbf{2}}$ & standard error \\
\hline $0.834^{\mathrm{a}}$ & 0.696 & 0.684 & 0.2986 \\
\hline
\end{tabular}

a predictors: constant, \#2mm (\%), $\mathrm{d}_{\mathrm{sm}}\left(\mathrm{g} \mathrm{cm}^{-3}\right), \mathrm{fn} / \mathrm{C}$.

dependent variable: $\sqrt[3]{\mathrm{UCS}}(7 \mathrm{~d})$.

TABLE 7. Analysis of variance for UCS (7d) model in jabre

\begin{tabular}{lccccc}
\hline \multicolumn{5}{c}{ ANOVA $^{\mathrm{a}}$} \\
\hline Model & $\begin{array}{c}\text { squares } \\
\text { Sum }\end{array}$ & $\begin{array}{c}\text { degrees of } \\
\text { freedom }\end{array}$ & average & F & sig. \\
\hline regression & 16.289 & 3 & 5.430 & 60.914 & $0.000^{\mathrm{b}}$ \\
remainder & 7.131 & 80 & 0.089 & & \\
total & 23.420 & 83 & & & \\
\hline
\end{tabular}

a dependent variable UCS(7d).

${ }^{\mathrm{b}}$ predictors: constant, \#2.0mm $(\%), \mathrm{d}_{\mathrm{sm}}\left(\mathrm{g} \mathrm{cm}^{-3}\right), \# 0.08 \mathrm{~mm} / \mathrm{C}$.

TABLE 8. Linear regression coefficients for UCS (7d) estimate model in jabre

\begin{tabular}{lccccccc}
\hline & \multicolumn{2}{c}{$\begin{array}{c}\text { no standard } \\
\text { coefficients }\end{array}$} & & \multicolumn{2}{c}{$\begin{array}{c}\text { standard } \\
\text { coefficients }\end{array}$} & & \\
\cline { 2 - 3 } Model & B & $\begin{array}{c}\text { standard } \\
\text { error }\end{array}$ & & & t & sig. \\
\hline constant & -4.111 & 1.739 & & -2.364 & 0.020 \\
$\mathrm{~d}_{\mathrm{sm}}\left(\mathrm{g} \mathrm{cm}^{-3}\right)$ & 2.777 & 0.892 & & 0.199 & 3.112 & 0.003 \\
$\# 0.08 \mathrm{~mm}$ & 0.171 & 0.013 & & 0.853 & 13.002 & 0.000 \\
$(\%) / \mathrm{C}$ & & & & & & \\
$\# 2.0 \mathrm{~mm}(\%)$ & -0.016 & 0.006 & & -0.171 & -2.525 & 0.014 \\
\hline
\end{tabular}

dependent variable: $\sqrt[3]{\mathrm{UCS}}(7 \mathrm{~d})$.
The model has a validity range of UCS (7d) and it has an interval scale between 0.7 and $3.6 \mathrm{MPa}$. Densities are between 2.20 and $1.80 \mathrm{~g} \mathrm{~cm}^{-3}$. The filler/ cement binder ratio is between 5.1 and 1.2. Finally, $2 \mathrm{~mm}$ sieving (medium sand and filler content) is between 54.3 and $34.1(\%)$.

\subsection{Compressive strength model rupture at fourteen days (14d) curing}

Table 9 describes a high value of the Pearson's correlation coefficient, which is 0.991 , as well as a low standard error of $0.0280 \mathrm{MPa}$ and a high coefficient of determination of 0.991 , thus proving high correlation.

Table 10 shows that Student's t-values are high and significant. There is a significant contribution of independents variables over UCS (14d).

This implies that the expression of the adjustment is complete [3]:

$$
\begin{aligned}
& \sqrt[3]{\operatorname{UCS}(14 \mathrm{~d})}=3.937 \mathrm{~d}_{\mathrm{sm}}+0.073 \mathrm{C} \\
& +0.019 \# 2.0 \mathrm{~mm}-7.665
\end{aligned}
$$

The model has a validity range. UCS (14 d) has an interval scale between 0.9 and $2.7 \mathrm{MPa}$. Density samples are between 2.01 and $2.08 \mathrm{~g} \mathrm{~cm}^{-3}$. Cement content is between 2.0 and 5.0 . Finally, $2.0 \mathrm{~mm}$ sieving (medium sand and filler content) is between 34.1 and $50.0 \%$.

TABLE 9. Determination coefficients for UCS (14d) model in jabre

\begin{tabular}{lccc}
\hline \multicolumn{3}{c}{ Summary model } \\
\hline $\mathbf{R}$ & $\mathbf{R}^{2}$ & adjusted $\mathbf{R}^{\mathbf{2}}$ & standard error \\
\hline $0.991^{\text {a }}$ & 0.982 & 0.977 & 0.0280 \\
\hline
\end{tabular}

\begin{tabular}{|c|c|c|c|c|c|}
\hline \multicolumn{6}{|c|}{ UCS (14d) ${ }^{a}$} \\
\hline \multirow[b]{2}{*}{ Model } & \multicolumn{2}{|c|}{$\begin{array}{c}\text { no standards } \\
\text { coefficients }\end{array}$} & \multirow{2}{*}{$\begin{array}{c}\begin{array}{c}\text { standards } \\
\text { coefficients }\end{array} \\
\beta\end{array}$} & \multirow[b]{2}{*}{$\mathrm{t}$} & \multirow[b]{2}{*}{ sig. } \\
\hline & B & $\begin{array}{c}\text { standard } \\
\text { error }\end{array}$ & & & \\
\hline constant & -7.665 & 0.622 & & -12.298 & 0.000 \\
\hline$d_{s m}\left(\mathrm{~g} \mathrm{~cm}^{-3}\right)$ & 3.937 & 0.325 & 0.527 & 12.097 & 0.000 \\
\hline $\mathrm{C}(\%)$ & 0.073 & 0.009 & 0.344 & 7.938 & 0.000 \\
\hline$\# 2.0 \mathrm{~mm}(\%)$ & 0.019 & 0.001 & 0.702 & 14.723 & 0.000 \\
\hline
\end{tabular}

a Predictors: constant, \#2.0mm (\%), C (\%), $\mathrm{d}_{\mathrm{sm}}\left(\mathrm{g} \mathrm{cm}^{-3}\right)$.

TABLE 10. Linear regression coefficients for UCS (14d) estimate model in jabre

${ }^{a}$ Dependent variable: $\sqrt[3]{ }$ UCS (14d). 


\subsection{Compressive strength model. Rupture at twenty-eight days curing (28d)}

As shown in Table 11 Pearson's correlation coefficient is 0.845 , which means that correlation is high. Dispersion, on the other hand, is low. For the fortythree lots of the representative sample, the determination coefficient obtained was 0.714 .

Table 12 also shows high values of Student's t-test within the 2.303-8.285 range, all of them significant. This means that the independent variables have significant effects on the dependent $\left({ }^{3} \sqrt{ } \mathrm{UCS}\right)$.

Therefore, the adjustment for UCS with $28 \mathrm{~d}$ rupture is as follows [4]:

$$
\sqrt[3]{\operatorname{UCS}(28 \mathrm{~d})}=1.934 \mathrm{~d}_{\mathrm{sm}}+0.037 \mathrm{C}
$$$$
+0.005 \# 2.0 \mathrm{~mm}-2.927
$$

The model has a validity range. UCS (28d) has an interval scale between 1.3 and $3.2 \mathrm{MPa}$. The density samples are between 1.98 and $2.10 \mathrm{~g} \mathrm{~cm}^{-3}$. The cement content is between 2.0 and 5.5. Finally,

TABLE 11. Determination coefficients for UCS (28d) model in jabre

\begin{tabular}{lccc}
\hline \multicolumn{3}{c}{ Summary model } \\
\hline $\mathbf{R}$ & $\mathbf{R}^{\mathbf{2}}$ & adjusted $\mathbf{R}^{2}$ & standard error \\
\hline $0.845^{\text {a }}$ & 0.714 & 0.693 & 0.0579 \\
\hline
\end{tabular}

a predictors: constant, \#2.0mm (\%), C (\%), $\mathrm{d}_{\mathrm{sm}}\left(\mathrm{g} \mathrm{cm}^{-3}\right)$.

TABLE 12. Linear regression coefficients for UCS (28d) estimate the jabre model

\begin{tabular}{lccccccc}
\hline & \multicolumn{2}{c}{$\begin{array}{c}\text { no standard } \\
\text { coefficients }\end{array}$} & & \multicolumn{1}{c}{$\begin{array}{c}\text { standard } \\
\text { coefficients }\end{array}$} & & \\
\cline { 2 - 3 } Model & B & $\begin{array}{c}\text { standard } \\
\text { error }\end{array}$ & & $\beta$ & t & sig. \\
\hline constant & -2.927 & 0.456 & & -6.425 & 0.000 \\
$\mathrm{~d}_{\mathrm{sm}}\left(\mathrm{g} \mathrm{cm}^{-3}\right)$ & 1.934 & 0.233 & & 0.714 & 8.285 & 0.000 \\
$\mathrm{C}(\%)$ & 0.037 & 0.009 & & 0.380 & 4.298 & 0.000 \\
$\# 2.0 \mathrm{~mm}(\%)$ & 0.005 & 0.002 & & 0.207 & 2.303 & 0.027
\end{tabular}

dependent variable: $\sqrt[3]{ }$ UCS $(28 \mathrm{~d})$.
$2.0 \mathrm{~mm}$ sieving (medium sand and filler content) is between $37.4-50.6 \%$.

\section{DISCUSSION}

The results of the different models were grouped into the significance matrix shown in Table 13. It displays the combinations of analyzed tests with their determination coefficients. In the case of nonrepresentative variables, with t-values below those of the other other variables, the numerical value has been replaced by ns (nonsignificant). Some terms have been removed due to their being quite obvious.

Student's t-coefficients show that the highest correlation is for the filler-cementitious binder ratio, with a positive trend. With the same percentage of cement, higher UCS is yielded by higher contents of fine aggregate. UCS is also proportional to the density of the sample, especially at $14 \mathrm{~d}$. The only association with a negative trend was screening 2 UNE sieve $(2 \mathrm{~mm})$ at $7 \mathrm{~d}$. Therefore, medium and fine sands yield lower resistance. This is probably due to its medium plasticity, although this is less significant. The t-statistic value for the $2.0 \mathrm{~mm}$ sieving at $14 \mathrm{~d}$ is also indicated; at this age UCS is more associated with the sand and filler medium content than with sample density. The cement content is more important at $14 \mathrm{~d}$ than at $28 \mathrm{~d}$, while at $7 \mathrm{~d}$ is not significant. According to this trend, the filler/ cement binder ratio is only significant at the first curing age (7d), not at the rest $(14,28 d)$.

Experimental results demonstrate that compressive strength is greatly influenced by the jabre conditions such as the $2.0 \mathrm{~mm}$ sieving (medium sand $\&$ filler content), with a validity range between 34.1 and $54.3 \%$. The density samples for jabre slightly increase between 1.90 and $2.14 \mathrm{~g} \mathrm{~cm}^{-3}$ with a significant increase of UCS and with a distribution range of 0.7 and 3.6 MPa. For the same granular material, UCS proves to be more influenced by cement content at $28 \mathrm{~d}$ than at $7 \mathrm{~d}$ rupture time. Therefore, the mechanical properties of the cement and jabre mixture should be assessed for UCS adjustment (28d).

Chuang et al. (23) have carried out experimental research on the stabilization of contaminated soils with Portland cement, also considering UCS. The

TABLE 13. Jabre models (characteristic curve, 7, $14 \& 28 \mathrm{~d}$ ) significance matrix

\begin{tabular}{lccccc}
\hline \multicolumn{7}{c}{ Student's t-coefficients $\mathbf{( t )}$} & & & \\
\hline & $\mathbf{d}_{\text {sm }}\left(\mathbf{g ~ c m}^{-\mathbf{3}}\right)$ & $\mathbf{C ~ ( \% )}$ & $\mathbf{\# 0 . 0 8 m m / C}$ & $\mathbf{\# 2 . 0 m m ( \% )}$ & $\mathbf{t}(\mathbf{d})$ \\
\hline characteristic curve $(\mathrm{d})$ & 12.037 & 6,413 & $\mathrm{~ns}$ & 8.084 & 6.698 \\
$7 \mathrm{~d}$ & 3.112 & $\mathrm{~ns}$ & 13.002 & -2.525 & --- \\
$14 \mathrm{~d}$ & 12.097 & 7.938 & $\mathrm{~ns}$ & 14.723 & --- \\
$28 \mathrm{~d}$ & 8.285 & 4.298 & $\mathrm{~ns}$ & 2.303 & --- \\
\hline
\end{tabular}

ns: nonsignificant (Student's t-value below that of the other variables). 
strength of treated soils has been improved through the application of cement. The strength of soil contaminated with $3 \%$ of oil, stabilized by an addition of $12 \%$ cement after curing for a 28 -day period increases to $0.5 \mathrm{MPa}$. The increase in the cement content of jabre reaches $5.5 . \%$, with a remarkable improvement of UCS to an average value of $2.3 \mathrm{MPa}$. Thus, the applicability of cement as an additive to treat oil-contaminated soils is similar to that of jabre. Amadi and Osu (24) describe the effect of curing time on strength development in black cotton soil - Quarry fines composite stabilized with cement kiln dust (CKD). Soil mixtures with 4\% CKD achieved an increase of about 1.25 the initial 0-day (i.e., immediately after preparation) strength after 7 days, which increased to 3.2 at 28 days. The influence of curing time on cementstabilized jabre soil is different, showing an improvement in UCS average values, which ranged from 1.7 $\mathrm{MPa}(7 \mathrm{~d})$ to $2.1 \mathrm{MPa}(28 \mathrm{~d})$. UCS (28d) is higher than those tested $7 \mathrm{~d}$ after preparation. There is no increase in UCS for the specimens made at 7 and $14 \mathrm{~d}$. For Li et al. (25), the strength of the cement-stabilized soil can be improved by the use of seawater. Compressive strength test results show that the strength of cementstabilized soil mixed with seawater is $50 \%$ greater than that mixed with freshwater at the $90^{\text {th }}$ day. With the addition of ultrafine silica fume, the unconfined compressive strength increases by close to $6.5 \%$ compared with seawater alone at the $90^{\text {th }}$ day. On this subject, further studies considering cement-stabilized jabre mixed with seawater and possibly ultrafine silica fume contents are necessary. Rahmi et al. (26) describes an investigation of water additive (W/A) ratio application on the strength of cement-stabilized. Peat soil at different moisture contents, which are $1210 \%, 803 \%$ and $380 \%$ were stabilized with cement by W/A ratio of $2.5,2.5,3.0,3.5$ and 4.0. The results show that there is an increase of UCS value as the decrease of W/A ratio (the increase of cement dosage) and the increase of curing time and peat moisture content. Research on the various cement-stabilized jabre, specimens does not report significant improvement in UCS with varied W/A ratio between $1.2-3.0$, other parameters such as dry density, granulometric curve or cement content being more relevant.

This paper shows how the soil developed from granitic rock can be greatly influenced by numerous variables. Therefore, the compressive strength of "in situ" cement-stabilized soils is not only affected by cement content or share density variables. The study has developed a procedure to identify the main characteristics of alluvial soils originated from granite weathered rocks and their influence at different times on compressive strength loosening when stabilized with cement.

\section{CONCLUSION}

The main conclusions drawn from this study are as follows:
- Jabre has evolved from granite, which means that there are many variations in its mechanical behavior that are difficult to control based on general specifications. It is necessary to adjust its resistance to simple compression versus sample density, the filler mineral-cement binder ratio and, finally, the fine sand aggregate.

- In general, the resistances obtained were higher than stabilized soil standard limits (1.5 MPa) for all percentages of the cement binder, even for the $3 \%$ minimum percentage.

- As a result, the sampling frame of the hardening curve model of cement-stabilized jabre was generated. This implies that the most significant variables are dry density over sample, cement content percentage and two millimeters sieving.

- The share density and the UCS have an empirical relationship. That density variations affect UCS has been shown on several occasions. Higher density values correspond with higher UCS. These variables are strongly associated.

- The experimental results demonstrate that UCS is significantly influenced by the jabre conditions of the $2.0 \mathrm{~mm}$ sieving. UCS shows a bigger influence of cement content at $28 \mathrm{~d}$ than at the $7 \mathrm{~d}$ rupture time. Therefore, for UCS (28d) adjustment, the mechanical properties of the cement-jabre mixture should be assessed.

\section{REFERENCES}

1. Garcia-Talegon, J.; Iñigo, A.C.; Vicente-Tavera, S.; Molina-Ballesteros, E. (2016) Silicified Granites (Bleeding Stone and Ochre Granite) as Global Heritage Stones Resources from Avila (Central of Spain). Geosci. Canada. 43 [1], 53-62. https://doi.org/10.12789/ geocanj.2016.43.087

2. Champiré, F.; Fabbri, A.; Morel, J.-C.; Wong, H.; McGregor, F. (2016) Impact of relative humidity on the mechanical behavior of compacted earth as a building material. Construc. Build. Mater. 110 [1], 70-78. https://doi. org/10.1016/j.conbuildmat.2016.01.027.

3. UNE-EN 13286-51. (Una Norma Española - European Norm). (2006) Unbound and hydraulically bound mixtures - Part 51: Method for the manufacture of test specimens of hydraulically bound mixtures using vibrating hammer compaction.

4. Ministry of Public Works. (2014) General Specifications for Roads and Bridges Works (PG-3). $5^{\text {th }}$ Part Pavements, 50-312.

5. UNE-EN 13286-41. (2003) Unbound and hydraulically bound mixtures - Part 41: Test method for the determination of the compressive strength of hydraulically bound mixtures.

6. UNE 103501. (1994) Geotechnics. Compaction test. Modified Proctor.

7. UNE 103900. (2013) In situ determination of density and moisture content of soil and granular materials by nuclear methods: low depths.

8. UNE-EN 933-2. (1996) Test for geometrical properties of aggregates. Part 2: determination of particle size distribution. Test sieves, nominal size of apertures.

9. UNE 103101. (1995) Particle size analysis of a soil by screening.

10. UNE 103103. (1994) Determination of the liquid limit of a soil by the Casagrande apparatus method.

11. UNE 103104. (1993) Test for plastic limit of a soil. 
12. Anagnostopoulos, C.A. (2015) Strength properties of an epoxy resin and cement-stabilized silty clay soil. Appl. Clay Sci. 114, 517-529. https://doi.org/10.1016/j. clay.2015.07.007

13. Niu, X.; Xie, H.; Sun, Y.; Yao, Y. (2017) Basic Physical Properties and Mechanical Behavior of Compacted Weathered Granite Soils. Inter. J. Geomechan. 17 [10]. https://doi.org/10.1061/(ASCE)GM.1943-5622.0000983

14. Wu, Y: Yamamoto, H.; Izumi, A. (2016) Experimental Investigation on Crushing of Granular Material in OneDimensional Test. Period. Polytech. Civil Engineer. 60 [1], 27-36. https://doi.org/10.3311/PPci.8028.

15. Kariyawasam, K.K.G.K.D.; Jayasinghe, C. (2016) Cement stabilized rammed earth as a sustainable construction material. Construc. Build. Mater. 105, 519-527. https://doi. org/10.1016/j.conbuildmat.2015.12.189.

16. Kasama, K.; Zen, K.; Iwataki, K. (2007) Highstrengthening of cement-treated clay by mechanical dehydration. Soils Found. 47 [2], 171-184. https://doi. org/10.3208/sandf.47.171.

17. Liu, Z.B.; Xie, S.Y.; Shao, J.F.; Conil, N. (2015) Effects of deviatoric stress and structural anisotropy on compressive creep behavior of a clayey rock. Appl. Clay Sci. 114, 491-496. https://doi.org/10.1016/j.clay.2015.06.039.

18. Saldanha, R.; Consoli, N.C. (2016) Accelerated Mix Design of Lime Stabilized Materials. J. Mater. Civil. Engin. 28 [3], https://doi.org/10.1061/(ASCE)MT.19435533.0001437 .

19. Fernández-Ledesma, E.; Jiménez, J.R.; Ayuso, J.; Corinaldesi, V.; Iglesias-Godino, F.J. (2016) A proposal for the maximum use of recycled concrete sand in masonry mortar design. Mater. Construc. 66 [321], e075. https://doi. org/10.3989/mc.2016.08414.

20. UNE 103808. (2006) Load test of plate soils.

21. Ministry of Public Works. Instruction for the reception of cements $R C$-16. (2016).

22. UNE-EN 13286-45. (2004) Unbound and hydraulically bound mixtures - Part 45: Test method for the determination of the workability period of hydraulically bound mixtures.

23. Yu, C.; Liao, R.; Zhu, C.; Cai, X.; Ma, J. (2018) Test on the stabilization of Oil-Contaminated Wenzhou Clay by Cement. Advanc. Civil Engineer. 2018, 9675479. https://doi. org/10.1155/2018/9675479.

24. Amadi, A.A.; Osu, A.S. (2018) Effect of curing time on strength development in black cotton soil - Quarry fines composite stabilized with cement kiln dust (CKD). J. King Saud Univ. - Engineer. Sci. 30 [4], 305-312. https://doi. org/10.1016/j.jksues.2016.04.001.

25. Li, Q.; Chen, J.; Shi, Q.; Zhao, S. (2014) Macroscopic and Microscopic Mechanisms of Cement-Stabilized Soft Clay Mixed with Seawater by Adding Ultrafine Silica Fume. Advanc. Mater. Sci. Engineer. 2014, 810652. https://doi. org/10.1155/2014/810652.

26. Rahmi, A.; Taib, S.; Sahdi, F. (2018) Investigation of the Application of Various Water Additive Ratios on Unconfined Compressive Strength of Cement-Stabilized Amorphous Peat at Different Natural Moisture Contents. Advanc. Civil Engineer. 2018, 1945808. https://doi. org/10.1155/2018/1945808 